\title{
¿Quién teme a la nación? Respuestas a Pereda, Velasco y Villoro
}

\author{
C. Ulises MOULINES \\ Seminar für Philosophie, Logik und Wissenschaftstheorie \\ Ludwig-Maximilians-Universität München \\ moulines@lrz.uni-muenchen.de
}

\begin{abstract}
RESUMEN: Después de un breve resumen de las tesis defendidas en mi "Manifiesto nacionalista" (Diánoia, no. 46, 2001), discuto sucesivamente las objeciones de mis críticos Pereda, Velasco y Villoro. Frente a Pereda, arguyo que las tres "desmesuras" que él atribuye al nacionalismo son igualmente incompatibles con mi posición. Con Velasco coincido en que un problema importante es el paso de una etnia a una nación; disiento de él cuando me atribuye el rechazo a los Estados multinacionales en general. Las diferencias con Villoro son casi exclusivamente semánticas, excepto con respecto a su ataque a la idea de un Estado nacionalmente homogéneo.
\end{abstract}

PALABRAS CLAVE: nación, nacionalismo, Estado multinacional, autodeterminación

\begin{abstract}
No se puede ver el mundo moderno tal cual es, a menos que uno reconozca la avasalladora fuerza del patriotismo, de la lealtad nacional. En ciertas circunstancias, ella puede derrumbarse; en ciertos niveles de civilización no existe; pero como fuerza positiva, no hay nada que pueda comparársele. [...] Además, debemos admitir que las divisiones entre una nación y otra están fundadas en diferencias reales de actitud. Hasta hace poco se consideraba apropiado pretender que todos los seres humanos son muy parecidos; pero, de hecho, cualquier persona capaz de usar sus ojos sabe que el comportamiento humano promedio difiere enormemente de un país a otro.
\end{abstract}

Adivine el lector quién es el autor de estas líneas: ¿algún nazi alemán, un fascista italiano, un chetnik serbio? No; se trata de George Orwell, militante socialista, acerbo crítico del imperialismo británico en la India, miembro de las Brigadas Internacionales que combatieron el fascismo en España, gravemente herido en el frente de Aragón por defender la causa del internacionalismo proletario. ${ }^{1}$ A pesar de estas credenciales, Orwell, quien

1 G. Orwell, The Lion and the Unicorn, Penguin Books, Nueva York, 1982 (1a. ed., 1941), pp. 35-36 (la traducción es mía). 
había vivido largo tiempo en diversos países de dos continentes, era "capaz de usar sus ojos" para ver lo que salta a la vista —al contrario de tantos "internacionalistas" antes o después, sobre todo después, de él. Todavía mucha gente no quiere ver lo que salta a la vista. Así que, en este asunto, como en tantos otros, vale la pena, para emplear otra frase de Orwell, "decir que dos y dos son cuatro".

La reacción de personas que en Europa leyeron mi "Manifiesto nacionalista" (en lo sucesivo abreviado como $M N$ ) ha sido, por lo que me he enterado, sintomáticamente variopinta: alguna lo consideró una provocación intolerable y no me ha dirigido la palabra desde entonces; otra lo tomó por una broma de mal gusto; alguna otra reaccionó con una sonrisa entre compasiva y preocupada que significaba algo así como: "iPobre Moulines, ahora sí que despegó definitivamente!"; otra me preguntó por qué gastaba yo tantas energías y argumentos en algo que en definitiva ya estaba en la Carta Fundacional de las Naciones Unidas (lo cual es esencialmente correcto), y otra, en fin, se mostró un poco decepcionada manifestando que todo lo que yo hacía era señalar con el dedo que "el rey anda desnudo" (lo cual también es esencialmente correcto). Hubo también algún lector, puedo decirlo para mi consuelo, que mostró su pleno acuerdo con las tesis de $M N$, con su no-trivialidad y con la conveniencia de hacerlas públicas.

Menciono estas experiencias porque, después de ellas, valoro aún más de lo que de por sí hubiera hecho, la amplitud de espíritu de los tres colegas, Carlos Pereda, Ambrosio Velasco y Luis Villoro, que en México se han tomado el tiempo y la molestia de examinar detalladamente los planteamientos de $M N$. Ninguno de ellos está plenamente de acuerdo, e incluso uno de ellos (Pereda) entiendo que está en desacuerdo frontal con mis tesis. Pero en cualquier caso aportan argumentos y precisiones que tratan de desenmarañar la cuestión, y sobre todo se toman en serio el hecho de que, para bien o para mal, los conceptos de nación y nacionalismo son lo bastante importantes (yo añadiría que son decisivos para el futuro próximo de la humanidad) como para que sean discutidos en serio, abiertamente, sosegadamente, y con los mejores pertrechos teóricos a nuestra disposición - sin importar si somos filósofos académicos que de ordinario se dedican a otras cosas. Creo que ellos sienten, como yo mismo, que ya no le podemos pasar la papa caliente al vecino; hay que acogerla en nuestras propias manos y no dejársela sólo a los periodistas y autores de best-sellers. (Que nuestro esfuerzo intelectual tenga o no un mínimo impacto en la "opinión pública" —o sea, en los mencionados periodistas y autores de best-sellers -, eso ya es otra cuestión; pero al menos nadie nos podrá reprochar que nos encerramos en la famosa torre de marfil.) Creo que, a pesar de nuestras divergencias en puntos concretos, en esto concordamos Pereda, Velasco, Villoro y yo: 
hay que inspeccionar con buenos bisturís conceptuales, y no de manera superficial, el tema de las naciones y los nacionalismos.

En Europa prácticamente no es posible emprender esta tarea en el ámbito intelectual-universitario. ${ }^{2}$ En la escasa medida en que autores europeooccidentales se toman la molestia de decir algo sobre el nacionalismo, lo hacen de dos maneras: o bien para denostarlo en los tonos más virulentos, o bien para emprender ciertos análisis histórico-sociológico-económicos sumamente eruditos y aburridos para averiguar si puede detectarse el surgimiento de un movimiento nacionalista en el siglo XviII en el Norte de Italia o en el siglo XIX en el Este del Imperio Austro-Húngaro. El porqué y el cómo de los problemas que se plantean actualmente en Irlanda del Norte, Escocia, Flandes, Bretaña, Euzkadi, Cataluña, Córcega, Saboya, Tirol del Sur —por no hablar de lo que ha ocurrido y sigue ocurriendo en las inmensidades del antiguo bloque soviético-, todo ello se deja en las manos de los susodichos periodistas, autores de best-sellers y rasgadores de vestiduras profesionales. Y la premisa en cualquier caso es siempre la misma: estas historias de naciones y nacionalismos son radicalmente ridículas y/o perversas $\mathrm{y} / \mathrm{o}$ a lo sumo interesantes desde un punto de vista museístico.

En mi opinión, por el contrario, el debate en torno a la "cuestión nacional" no debería abandonarse enteramente a los periodistas y políticos que se ocupan del día a día (aunque, naturalmente, sería meritorio que ellos se tomaran también la cuestión con serenidad), ni tampoco sólo a psicopatólogos o museógrafos. La temática revela, a mi parecer, un grado suficientemente alto de complejidad y significación para el estudio de los asuntos humanos como para que también el filósofo (sea "filósofo teórico" o "práctico") asome su nariz fuera de la torre de marfil y le eche una ojeada analítica al asunto. Responder a este reto, aunque fuera de modo fragmentario y provisional, fue el objetivo de mi "Manifiesto". Y es estimulante constatar que tres apreciados colegas latinoamericanos tampoco han desdeñado recoger el guante.

No es éste el lugar para repetir las tesis defendidas en $M N$. Por lo demás, ellas han sido resumidas de manera intachable en la contribución de Ambrosio Velasco a este volumen, y el lector que no tenga el tiempo o las ganas de leer el texto entero de $M N$ puede acudir a dicho resumen. Antes de pasar a

2 Por "Europa" entiendo aquí, de entrada, España, Francia y Alemania, países de los que tengo conocimiento de primera mano respecto de estas cuestiones; pero estoy persuadido de que mi impresión puede generalizarse a toda la Europa Occidental -iaunque, por supuesto, no a la Europa Centro-Oriental y Oriental, donde a ningún intelectual en su sano juicio se le ocurriría afirmar que la preocupación por la "cuestión nacional" es mero producto de mentes calenturientas o trasnochadas. (Las causas histórico-políticas de esta diferencia de apreciación entre los europeos occidentales y los orientales creo que son obvias y no merecen mayor comentario.) 
las respuestas detalladas a mis tres críticos, no obstante, quisiera sólo hacer unas brevísimas observaciones sobre la perspectiva asumida en $M N$.

La primera (y más extensa) porción de mi ensayo es de carácter fundamentalmente teórico, mientras que la segunda representa un ejercicio de filosofía práctica. El enfoque teórico consiste en argumentar en favor de la tesis ontológico-epistemológica según la cual el predicado " $x$ es una nación" se aplica, al menos en un gran número de casos, a entidades que tienen una existencia real, si bien este predicado es de carácter teórico (en el sentido de la clásica filosofía de la ciencia) y por tanto no reducible a predicados observacionales o "fenoménicos" - lo cual le da al concepto de nación (o al de etnia, al que se subordina) ese carácter "esquivo y misterioso" que le atribuye uno de los etnólogos que cito en $M N$ (Lincoln Allison). Para articular esta idea esbozo en forma "axiomática" una "miniteoría de etnias y naciones", MEN. Mi contrincante en esta parte del ensayo es el negacionista, quien se caracteriza por afirmar que, o bien el predicado " $x$ es una nación" es extensionalmente equivalente al predicado " $x$ es un Estado", o bien se aplica sólo a entidades "mitológicas" (es decir, no se aplica a nada).

La segunda parte de $M N$ saca las consecuencias ético-políticas de MEN al combinar esta teoría "descriptiva" con un principio "normativo" de muy amplio alcance: el principio del valor intrínseco de la pluralidad del ser, VIPS. La combinación de MEN con VIPS da como resultado el nacionalismo: es bueno que haya entidades a las que se aplica el predicado " $x$ es una nación", en contra de lo que sostiene el contranacionalista, quien es alguien que no niega la existencia real de las naciones, pero las considera entidades nefastas para el buen desarrollo de la humanidad, entidades que hay que eliminar. (En los debates sobre el nacionalismo se suelen confundir el negacionismo y el contranacionalismo; incluso un mismo autor puede defender ambos a la vez - lo cual revela, dicho sea de paso, el bajo nivel de precisión conceptual con el que suelen conducirse estos debates.)

Negacionismo y contranacionalismo son las dos versiones clásicas del antinacionalismo en general; en $M N$ pretendo haber refutado ambas y por ello abogo por el nacionalismo.

Paso ahora a discutir las objeciones de mis críticos, por riguroso orden alfabético.

\section{AD PEREDA}

No está siempre claro en el texto de Pereda (pp. 119-136) si su crítica del nacionalismo está dirigida contra las tesis desplegadas en $M N$ o apunta más bien a ciertos peligros que conlleva una supuesta posición nacionalista ajena a mis tesis. Algunos pasajes de su texto critican abierta y explícitamente mi posición; pero otros, los más sustanciales, atañen posiciones que no sólo 
me son completamente ajenas, sino que yo estaría dispuesto a rechazar de manera igualmente tajante que Pereda. Esto último es especialmente cierto para lo que Pereda denomina "las desmesuras del nacionalismo". Estoy completamente de acuerdo con él en que hay que oponerse a las desmesuras, no sólo con respecto al nacionalismo, sino con respecto a cualquier otra cosa. El peligro de degenerar en actitudes o comportamientos desmesurados no es prerrogativa del nacionalismo y ni siquiera de los "ismos" en general (como parece sostener Pereda al comienzo de su artículo), sino que es un riesgo universal del ser humano: gustar del tequila o de los baños de vapor, en sí mismo no es particularmente pernicioso; pero si todas las noches nos tomamos una botella de tequila y todos los días nos los pasamos en un hammam, tales desmesuras podrán tener sin duda graves consecuencias. Señalar que el nacionalismo, el amor a la patria, puede derivar hacia peligrosas desmesuras, es correcto pero banal. Lo mismo puede decirse de cualquier otra actitud, incluso de actitudes consideradas excelsas, como puede ser el amor de una madre a su hijo.

Supongo que Pereda no quiere convencernos de esta banalidad, pues para ello sin duda podría haberse ahorrado el esfuerzo. Supongo que de lo que quiere convencernos es de que el nacionalismo, más que cualquier otra corriente político-cultural comparable, es especialmente proclive a degenerar en ciertas desmesuras a las que hay que oponerse vigorosamente; y, en particular, que mi defensa del nacionalismo en $M N$ puede (io debe?) conducir a dichas desmesuras. Es decir, parece que Pereda quiere sostener la tesis de que cualquier posición en favor del nacionalismo, como no sea la de un nacionalismo folclórico y totalmente inocuo, que se reduzca al gusto por la paella o los chiles en nogada (sus ejemplos), conduce nolens volens a las execrables desmesuras que él ataca. Digo "parece", porque nunca lo afirma así explícitamente. Pero algunos pasajes sugieren claramente esta línea de argumentación. Así, por ejemplo, en la página 122:

por estos usos de la palabra "nacionalismo", que seguramente pocos querrán objetar [a saber, los ejemplificados por los chiles en nogada], casi nadie discute, ni sale a la calle, ni chilla, ni se da de golpes; tampoco incluye la palabra en el nombre de un partido político, ni va a la guerra, ni escribe "manifiestos nacionalistas". Para defender [...] a Cervantes o a los chiles en nogada, nadie improvisa pelotones de fusilamiento.

Por el contrario, los usos de la palabra 'nacionalismo' que van más allá de Cervantes y los chiles en nogada "construyen un concepto de desmesura y la gente motivada por él sale a la calle y hace cosas mucho menos compartibles por otros" (loc. cit.). 
Aunque de una manera retóricamente alambicada, este pasaje sugiere la siguiente línea de argumentación: defender un nacionalismo algo más sustancial que ciertos gustos literarios o gastronómicos, y en particular escribir "manifiestos nacionalistas", es defender un nacionalismo desmesurado que conduce inexorablemente a los pelotones de fusilamiento. Y como los pelotones de fusilamiento son radicalmente malos, se sigue de ahí que un nacionalismo que vaya más allá de los chiles en nogada es radicalmente malo. Debo responder a esta argumentación con tres puntualizaciones.

En primer lugar, mi buen amigo Carlos Pereda puede dormir tranquilo. El propósito de mi "Manifiesto nacionalista" no era "improvisar pelotones de fusilamiento"; para empezar, porque carezco del know-how para tal empresa, y para terminar, porque no sé en nombre de qué nación debería yo hacerlo. Mi propósito no era defender el nacionalismo de esta o aquella nación en detrimento de otra, sino defender el nacionalismo para todas las naciones de la Tierra.

En segundo lugar, la cuestión de los "pelotones de fusilamiento" es un asunto muy delicado desde un punto de vista histórico-político. Pelotones de fusilamiento los ha improvisado mucha gente a lo largo de la historia, no sólo los nacionalistas, sino también sus adversarios y muchos otros que no tienen nada que ver con la cuestión del nacionalismo. No se le puede colgar el sambenito sólo a uno de los personajes de la película (ello, por cierto, sería una desmesura). Por lo demás, incluso en los casos en los que los nacionalistas han tomado las armas, yo no me atrevería a condenarlos a rajatabla en todos los casos, en aras de algún principio ético abstracto que se haya pergeñado en la confortable paz de los claustros universitarios. Tanto el resistente mexicano Benito Juárez en los años 1860, como el resistente francés Jean Moulin en los años 1940 (dos nacionalistas en mi acepción), se sintieron obligados a "improvisar pelotones de fusilamiento" para defender a sus respectivas naciones contra los "masiosares" respectivos que se les habían colado en casa; Pereda debería aportar argumentos más fuertes que los que presenta en su artículo para convencernos de que en ambos casos (y en tantos otros similares que podrían citarse) se trató de acciones intolerablemente "desmesuradas". Entraríamos aquí en una problemática por lo menos igual de vasta y compleja que la del nacionalismo: la del pacifismo radical, es decir, la posición según la cual "improvisar pelotones de fusilamiento" siempre y en cualquier circunstancia es execrable. Sospecho que Pereda, además de antinacionalista radical, es también pacifista radical; o, más exactamente, puedo imaginar que toma una posición radicalmente antinacionalista porque es radicalmente pacifista, es decir, porque cree que cualquier forma mínimamente sustancial de nacionalismo es incompatible con el pacifismo. Las detalladas descripciones que da en su artículo de las atrocidades co- 
metidas por los nacionalsocialistas alemanes y los chetniks serbios (de cuya realidad no tiene que persuadir al autor de estas líneas) parecen indicar que éste es ciertamente el núcleo de su argumentación: 1) cualquier nacionalismo que vaya más allá de un mínimo folclórico conduce en definitiva a la guerra (premisa histórico-empírica); 2) la guerra es siempre mala (pacifismo: premisa axiológica); luego, por modus tollens práctico, 3) cualquier nacionalismo no estrictamente folclórico es siempre malo. ${ }^{3}$

Desde un punto de vista lógico, el argumento expuesto es perfectamente correcto. La validez de su conclusión depende, sin embargo, de que aceptemos la validez de sus dos premisas. For the sake of the argument, vamos a presuponer la validez de la segunda premisa: el pacifismo radical es la posición correcta sin cortapisas en materia política, al menos cuando se trata de la cuestión nacional; no sólo Hitler y Milosevic, sino también Bolívar, Morelos, Juárez, Garibaldi, los resistentes polacos y el maqui francés, los mau-mau de Kenya y el FLN argelino, el Viet-Cong, la OLP, la SWAPO de Namibia y el FRELITIM de Timor, y tantos otros que han hecho fusilar o saltar por los aires a los adversarios extranjeros que se les habían metido en casa, todos ellos fueron o son energúmenos criminales de guerra. Sea. No obstante, queda por discutir todavía la primera premisa del argumento: ¿es cierto que el nacionalismo es, por su raíz misma, incompatible con el pacifismo? Me parece evidente que la respuesta es: no; no lo es, ni desde un punto de vista teórico, ni desde un punto de vista empírico. Empíricamente, podemos constatar con relativa facilidad que, cuando se da cierto grado de sensatez y buena voluntad por ambas partes, la nación $A$ puede independizarse o al menos adquirir un alto grado de autonomía respecto del Estado (hegemónico) $B$ sin pegar un tiro. (Ejemplos recientes: $A=$ Eslovaquia, $B=$ Checoslovaquia; $A=$ Quebec, $B=$ Canadá; $A=$ Estonia, $B=$ Unión Soviética). ${ }^{4}$ Admito que estos ejemplos son, lamentablemente, escasos. Casi

3 Esta argumentación (si Pereda la acepta como reconstrucción de su posición) goza efectivamente de un amplio consenso entre los intelectuales europeos, particularmente alemanes, que son invariablemente pacifistas y antinacionalistas —o al menos gozaba de él hasta el 11 de septiembre de 2001. Después de esta fecha, los intelectuales europeos, y en particular alemanes, descubrieron azorados que sus amigos gringos, intelectuales o no, de izquierdas o de derechas, por un lado hacían gala de un profundo amor a la patria y de un nacionalismo sin complejos, y por otro les pedían su solidaridad, al menos moral, a los europeos para poder ir a matar talibanes con entera libertad. Ante esta inesperada situación, los intelectuales europeos en cuestión, tan vehementes hasta hace poco cuando se trataba de echar pestes contra el nacionalismo croata, irlandés, vasco o el de otros pequeños pueblos "premodernos", se han sumido en un ruidoso silencio.

${ }^{4}$ Reconozco que este último ejemplo es un poco artificioso: los estonios lograron zafarse de los soviéticos (es decir, rusos) sin pegar un tiro, entre otros factores, porque poco antes los lituanos lo habían logrado teniendo que responder a los balazos de las fuerzas soviéticas con otros balazos, en lo cual murieron algunas personas; y el Estado soviético no quiso repetir el 
siempre, la nación $A$ ha logrado su independencia o un alto grado de autonomía respecto del Estado $B$, entre otras cosas, gracias a los tiros y las bombas. Pero en la inmensa mayoría de estos casos, la responsabilidad incumbe, en primera instancia, a los dirigentes del Estado $B$ por su actitud intransigente y opresiva. Y entonces es injusto echarles la culpa (o toda la culpa) a los nacionalistas de $A$ y ninguna a los antinacionalistas (hegemonistas) de $B$.

De todos modos, bastan algunos ejemplos afortunados para socavar empíricamente la tesis según la cual los objetivos del nacionalismo siempre llevan consigo la violencia armada. Pero es que, además, desde un punto de vista teórico general, no hay ninguna razón para que ello sea así. Para promover los objetivos político-culturales del nacionalismo existe un amplio espectro de posibilidades más allá de la mera preferencia por los chiles en nogada, pero más acá de los fusilamientos, incluso en los casos, por desgracia innumerables, en los que el Estado hegemónico $B$ no quiere atender las aspiraciones de la nación $A$ : la creación de partidos y asociaciones político-culturales, las campañas de prensa, las manifestaciones callejeras (los "chillidos" de los que Pereda habla despectivamente), los boicots, las huelgas y otras medidas parecidas por parte de $A$ pueden llegar a impresionar a los políticos hegemonistas de $B$, al menos si $B$ es un Estado relativamente democrático.

Probablemente, Pereda nos dirá que todo eso tampoco le interesa. Cualquier forma de nacionalismo, aunque no sea violenta, en cuanto vaya más allá de inofensivas preferencias más o menos folclóricas, sale sobrando. La razón, al parecer, es la siguiente. Cualquier idea mínimamente sustancial de nacionalismo lleva a las tres desmesuras catastróficas que inspiran el título de su artículo. Como la idea de nacionalismo que propugno en $M N$ pretende ser ciertamente más sustancial que el mínimo folclorismo que es lo máximo que Pereda está dispuesto a tolerar, se desprende que su reproche de desmesura también se aplicaría a mi propuesta. Veamos si este reproche está realmente justificado.

La primera desmesura que Pereda le achaca al nacionalismo es lo que podríamos llamar el "monopolio axiológico de la nación": la nación sería la única fuente de valores que el nacionalista admite para el individuo - "la circunstancia 'nación' es la única que importa" (Pereda, op. cit., p. 122). Pues bien, no creo que un lector imparcial de $M N$ saque esta conclusión. Ya de entrada doy una lista de sentimientos de filiación estructuralmente análogos e igualmente respetables que el amor a la patria: amor propio, amor a la familia, amor a la libertad y amor al conocimiento. Esta lista por supuesto es abierta. No tengo inconveniente en prolongarla cuanto Pereda apetezca. 
Podemos añadir incluso filiaciones que, aunque no todos compartamos, deben ser consideradas igualmente respetables y dignas de preservación para quien se sienta adscrito a ellas: por ejemplo, hacia una determinada comunidad religiosa, hacia un determinado ideal político-social, hacia un estilo artístico, etc., etc. El nacionalista no es alguien que desea que el amor a la patria barra con todo lo demás, alguien que pretende que, en aras de una nación, olvidemos nuestra dignidad personal, abandonemos la familia, disfrutemos de los campos de concentración y prefiramos vivir en la ignorancia. Lo único que pretende el nacionalista es que se respete su amor a su nación, entre otras cosas, y que no se le lancen anatemas por ello, que no se le ridiculice, que se le deje fomentar las formas de vida y de cultura que él identifica con su nación y con las que él se siente identificado. Ni de la teoría MEN ni del principio VIPS, por los que abogo en $M N$, se desprende en absoluto que al nacionalista le está vedada la pluralidad axiológica aquí descrita y que Pereda apetece.

La segunda desmesura perediana se refiere a las mitologías inventadas por los nacionalistas para fundamentar su idea de nación. Pereda distingue aquí dos tipos de mitos: el "primordialismo" y el "perennalismo". El primordialismo concibe la nación como unidad biológica (raza), mientras que el perennalismo la concibe como entidad histórica pero permanente. En $M N$ creo haber dejado bien claro que mi concepto de etnia, y por tanto su derivado, el de nación, no es equivalente al de raza ( $M N$, p. 96) y que entiendo ambos conceptos básicamente como nociones culturales. Así que de "primordialista", nada. ${ }^{5}$

Si por "perennalismo" se entiende la tesis según la cual las naciones son entidades surgidas históricamente pero que, una vez constituidas, son inmutables y "eternas", estoy de acuerdo con Pereda en que tal tesis es empíricamente inverosímil (prefiero el calificativo "inverosímil" al de "mitológico", que es innecesariamente polémico). Éste es justamente el sentido del "axioma" 6) de MEN: "Las etnias (y por tanto las naciones) son entidades genidénticas $[\ldots]$ nacen, se desarrollan y mueren" ( $M N$, p. 100). Está claro

${ }^{5}$ Ello no significa que considere evidente que el concepto de raza es totalmente inútil para estudiar el comportamiento humano y mucho menos que sea "mitológico", como parece sugerir Pereda. Es quizás "políticamente incorrecto" recordarlo, pero a mi modo de ver, hay diferencias fenotípicas notorias entre un habitante promedio de Islandia y otro de Zambia. No puede excluirse a priori que estas diferencias tengan una correlación estadística significativa con las diferencias de comportamiento y mentalidad, aunque tampoco es seguro que ello sea así (desconozco si hay estudios serios sobre este tema tabú). En cualquier caso, lo que creo —y así lo afirmo explícitamente en $M N$ - es que las diferencias raciales, aunque quizás sean relevantes para otras cuestiones antropológicas, probablemente no lo son para la cuestión del nacionalismo, por la simple razón de que la inmensa mayoría de naciones actuales son racialmente mestizas. 
que este "axioma" es incompatible con el perennalismo. Como nacionalista, no tengo por qué creer que mi nación es eterna e inmutable. Basta con que crea que mi nación surgió en un periodo histórico determinado, que aspire a contribuir a su desarrollo, y que desee que, si ha de morir, se muera en paz y no por ser asesinada (o "integrada", como reza el eufemismo).

Aún menos puedo entender cómo Pereda se vio llevado por la lectura de mi ensayo a sospechar en él lo que denomina la "tercera desmesura" del nacionalismo: un mundo cuasi-leibniziano de naciones cual mónadas encerradas cada una en sí misma y sin comunicación con las demás. En diversos pasajes de mi texto expreso mi ideal (desgraciadamente utópico) de una auténtica "Organización de las Naciones Unidas" en vez de la actual "Organización de Estados (mal) Unidos", vulgarmente conocida como ONU. Y creo que la paráfrasis marxiana del final de mi "Manifiesto" no deja lugar a dudas al respecto: "Naciones de todo el mundo: uníos". Parecería que ante ello sobran los comentarios. Pero quizás Pereda sospeche que el lema sólo vale de boca para afuera y que, detrás de esas bellas palabras, se agazapa el espectro del "todos contra todos". La razón sería que, diga lo que diga el nacionalista en favor de una multiplicidad de naciones, en el fondo de su corazón a él únicamente le interesa la suya propia -las demás serían sólo factores perturbadores que hay que ignorar en lo posible-; el verdadero lema del nacionalista en este contexto no sería así mi paráfrasis marxiana, sino por el contrario "la máxima sectaria: Siempre es bueno más de lo mismo" (Pereda, op. cit., p. 131).

Ante esta interpretación del nacionalismo inter-nacionalista que propongo, sólo puedo exclamar: iQué remedio! Siempre es posible sospechar que detrás de cualquier declaración explícita de buena fe se ocultan quién sabe qué propósitos siniestros. Ante tales sospechas, de nada sirven los argumentos, y la discusión filosófica deja de tener sentido. Por ello, llegados a este punto de la discusión, sólo me queda concluir esta réplica al antinacionalismo de mi amigo Pereda con una confesión personal, es decir, un argumentum ad personam (pecado capital para cualquier buen filósofo), pero quizás ello lo persuada mejor de la sinceridad de mi nacionalismo internacionalista: en efecto, me considero particularmente afortunado de poder vivir actualmente en Centroeuropa, en esa región del globo donde basta recorrer un par de centenares de kilómetros para trabar conocimiento con cinco o seis naciones diferentes. iQué delicia tomar el automóvil en Baviera y encontrarse en menos de dos horas en Chequia, o tomarlo en otra dirección y, en el mismo lapso de tiempo, toparse con Italia, o en otra dirección todavía, y parar en Suiza, o aún en otra, y hallarse en Francia! En un radio de unos pocos centenares de kilómetros, el nacionalista inter-nacionalista autor de estas líneas puede gozar de media docena de lenguas diferentes, 
formas arquitectónicas diferentes, gustos melódicos y culinarios diferentes, mentalidades y formas de vida diferentes; en una palabra, de media docena de naciones genuinamente diferentes. ¿Es esto un desastre? Para mí (y sospecho que hasta para Pereda cuando se olvida de que es un filósofo "universalista") se trata de una experiencia sumamente enriquecedora...

Ciertamente, estas naciones tuvieron en el pasado conflictos entre sí. Pero de eso hace ya bastante tiempo y, desde entonces, los habitantes de estos países han aprendido a respetarse mutuamente a través de negociaciones y compromisos, y a valorar cada uno la cultura del otro, preservando al mismo tiempo su identidad nacional. Good fences make good neighbours! Por esta razón, considero que el privilegio de vivir en Múnich es infinitamente superior al de vivir en Kansas City. Una manera quizás poco sutil, pero gráfica, de expresar el ideal al que modestamente quiso contribuir mi "Manifiesto" es que se trata de fomentar un mundo que se parezca lo más posible a Europa Central y lo menos posible al Midwest... Si este ideal es una "desmesura", entonces efectivamente soy "desmesurado", pero se trata de una desmesura sostenida para combatir otra desmesura terrible: lo que podríamos llamar el aumento de la "entropía cultural".

\section{AD VELASCO}

Mi respuesta al artículo de Ambrosio Velasco (pp. 137-147) será más breve que la correspondiente al de Carlos Pereda; no porque considere que contiene menos observaciones interesantes, sino porque en lo esencial estamos de acuerdo - aparte de ciertas cuestiones de detalle que pasaré a discutir a continuación. Por lo demás, Velasco presenta, en la primera parte de su artículo, una sinopsis excelente de mi posición en $M N$. Yo no la podría haber hecho mejor (o, más exactamente, yo la habría hecho peor, pues siempre es difícil para un autor sintetizar adecuadamente sus propias ideas). ${ }^{6}$

Pasada la exposición inobjetable de las tesis formuladas en $M N$, Velasco presenta sus observaciones críticas, de las cuales la más importante, según él mismo dice, es que mi "miniteoría de etnias y naciones", MEN, no aborda el problema de cómo una etnia dada, que aún no era nación, en determinado momento se transforma en una verdadera nación. Mi respuesta a Velasco en este punto es simple: tiene toda la razón. Ésta es una laguna en mi enfoque. Precisamente por ello, entre otras cosas, es por lo que califiqué a

${ }^{6}$ Aprovecho aquí la ocasión para sumarme al homenaje emotivo y justo que hace Velasco a la memoria de Elia Nathan. Durante mis años en México, saqué siempre provecho del espíritu crítico de Elia. Tuvimos numerosas y sabrosas "broncas" teórico-filosóficas, que culminaron en los sendos artículos que Velasco menciona. Esas "broncas" no empañaron, sino que, al contrario, creo que afianzaron nuestro mutuo afecto. En mi memoria quedará siempre el recuerdo entrañable de esa aguda y bondadosa contrincante. 
mi teoría de mini. ${ }^{7}$ Mi propósito fue sólo formular un esbozo muy esquemático, y sobre todo casi exclusivamente en perspectiva sincrónica. Se trataba de estimular a otros, mejor pertrechados que yo para abordar cuestiones etnológicas y politológicas (Ambrosio Velasco podría ser uno de ellos), para que profundicen en el tratamiento teórico de la cuestión nacional. Aquí me limitaré a lanzar una hipótesis especulativa (aunque creo que tiene cierta base histórica), hipótesis por cierto ya insinuada en la última parte de $M N$ : una etnia se convierte en nación cuando una porción considerable de sus miembros (el porcentaje exacto es asunto de los científicos empíricos) cobra conciencia de que su identidad, su Lebensform con todo lo que ella conlleva, se ve amenazada, o al menos cuestionada o molestada, por agentes externos - principalmente otros grupos humanos, pero a veces quizás también cambios climáticos, catástrofes naturales y acontecimientos parecidos. Es entonces cuando la etnia en cuestión se percata de que necesita desarrollar un programa de acción política y de organización jurídico-institucional que muchas veces, aunque no siempre, desembocará en la creación de un Estado.

Creo que ésta es una de las posibles causas de la transformación de una etnia en nación. Puede haber sin duda otras. (No creo que haya sólo un factor que tener en cuenta en este asunto.) El negacionista que critico en $M N$ propone, naturalmente, una explicación muy distinta para la conversión de una etnia en nación (suponiendo que él admita siquiera la realidad de las etnias): ciertas elites corruptas y manipuladoras, que quieren afianzar su poder y enriquecerse a costa de los demás, les lavan el cerebro a las masas crédulas, con la probable complicidad de tenebrosos y remotos diplomáticos y hombres de negocios extranjeros, para hacerles creer a las masas que constituyen una nación necesitada de una organización política propia. Podríamos llamar a esta hipótesis "la teoría del complot en la formación de naciones". Parece que Pereda favorece en su artículo esta teoría, al menos para las naciones latinoamericanas (cfr. su descripción de los casos de Uruguay, Argentina y América Central).

Por las razones ya expuestas en $\mathrm{MN}$, no creo en la teoría del complot; o, para ser más precisos, creo que su poder explicativo es muy pobre y que en la mayoría de los casos es altamente inverosímil. Después de todo, ni las masas suelen ser tan crédulas, ni tan poderosos las elites corruptas y el Foreign Office. Sin embargo, estoy dispuesto a admitir que la "manipulación desde arriba" ha desempeñado algún papel en la formación de naciones en algunos casos. Pero, incluso cuando ello haya sido así, una vez que una nación se ha constituido y ha empezado a desarrollar una vida propia, se da un salto cualitativo que, en general, es irreversible. Velasco, con razón,

7 Al menos en este sentido sigo sin ser "todólogo"... pace Elia y pace Ambrosio. 
quisiera averiguar más cosas acerca de los factores que inciden en este salto cualitativo. A este deseo comprensible sólo puedo responder que quizás él u otros puedan aclarar mejor esta cuestión.

Aunque no estoy seguro de interpretar a Velasco correctamente en este punto, parece que él quiere emitir la hipótesis de que en la constitución de una nación tiene un papel de primer orden la llamada "sociedad civil". No tengo nada en contra del concepto de "sociedad civil". Lo que no me queda claro es su vínculo con el concepto de nación. Una posible manera de entender "sociedad civil" es simplemente como equivalente extensional de "nación"; pero entonces sigue en pie el problema del "salto cualitativo" de una etnia a una sociedad civil. O bien, el concepto de nación y el de sociedad civil son distintos: la sociedad civil de un Estado $X$ sería el conjunto de ciudadanos y asociaciones de $X$ cuya actuación es, en principio, autónoma con respecto a las instituciones de $X$. ¿Pero cuál es la relación de esta entidad con la nación? En un Estado multinacional podría haber una sola sociedad civil, pero varias naciones. Consideremos el siguiente ejemplo esquemático (que es quizás aquel en que está pensando Velasco, dadas las recientes experiencias mexicanas). Tenemos un Estado hegemónico $A$ que administra una nación mayoritaria $B$ y, además, una etnia (o nación) minoritaria $C \neq B$. La sociedad civil de $A$ se hace paulatinamente consciente de que las instituciones de $A$ no sólo no responden a una serie de aspiraciones básicas de $B$, sino tampoco a las de $C$, por lo que se decide a luchar tanto por lo que le interesa a $B$, como por lo que le interesa a $C$. En este proceso, $B$ demuestra tener más perspicacia, sensibilidad y generosidad que $A$; pero no por ello resulta $B=C$. Y, en todo caso, el enigma del "salto cualitativo" de la etnia a la nación seguirá intrigándonos.

Otras divergencias con Velasco son menores o se deben a malentendidos. Por ejemplo, no veo una necesidad conceptual o metodológica para distinguir dos tipos de naciones, "estatal" y "cultural". En el sistema conceptual que propongo, toda nación es una entidad cultural, cualesquiera que hayan sido los factores conducentes a su formación; lo que ocurre es que algunas naciones disponen de un Estado y otras no, eso es todo. Y de ahí las broncas.

Mi esquema teórico, aplicado al caso de México, que es el que más interesa a Velasco, vendría a dar el siguiente resultado, que me permito exponer con cierto detalle, a pesar de mis conocimientos insuficientes en la materia (y aún a riesgo de que me apliquen el artículo 33 de la Constitución la próxima vez que vaya a México). He aquí mi "Breve Historia General de México". Antes de Cortés, había en el territorio que ahora llamamos "México" un gran número de etnias claramente diferenciadas, un cierto número de las cuales había dado ya el "salto cualitativo" al estatuto de nación (autoconciencia política, formas de vida defendidas enconadamente frente a 
las demás, cultivo sistemático de la religión, la lengua, la literatura y el arte propios, territorio relativamente bien delimitado, etc.) e incluso de Estado (formas jurídico-administativas claramente articuladas, con o sin guerras, diplomacia, etc.). ${ }^{8}$ La incursión de Cortés y su pandilla arrasó con todo eso, y acabó con los Estados indígenas y con la mayoría de las naciones, aunque no con las etnias (siempre es más difícil acabar con una etnia que con una nación). El territorio en cuestión pasó a formar parte de un Estado (terriblemente) hegemónico en mis términos, o "etnocrático" en los términos de Stavenhagen que prefiere Velasco: el Estado español o "Castilla", como se llamaba entonces oficialmente; una sola nación, la castellana, decidía todo lo esencial. A lo largo de trescientos años, en un proceso paulatino, doloroso e involuntario, se fue constituyendo en ese territorio, y por tanto dentro del Estado español, una nueva etnia. A esta etnia la llamamos hoy día "los mexicanos". Algunos prefieren decir que se trata de una nación "mestiza". Considero esta terminología inapropiada. En primer lugar, porque casi todas las etnias y naciones del mundo hoy día son "mestizas" en el sentido biológico; en segundo lugar, porque para la constitución de la, primero, etnia y, luego, nación mexicana, no importa en absoluto averiguar cuántos genes de un individuo provenían de un antepasado astur y cuántos de otro zapoteca. El caso es que esta etnia poco a poco cobró conciencia de nación y, a principios del siglo XIX, después de improvisar unos cuantos pelotones de fusilamiento, se emancipó del Estado hegemónico español y se dio a sí misma un nuevo Estado... nuevamente hegemónico, porque en él fueron simplemente ignoradas largo tiempo (al menos hasta los años 1930) las demás etnias y los restos de naciones que habían sobrevivido al holocausto propiciado por la Madre Patria. Desde entonces, la situación ha cambiado un poco. Se ha reconocido oficialmente la identidad y el derecho a la existencia de las etnias, aunque no el de las naciones minoritarias, que abarca el Estado. Tenemos así en la actualidad el siguiente resultado: un solo Estado, denominado "Estados Unidos Mexicanos", que administra la vida de una nación super-mayoritaria y (hasta ahora) bastante hegemónica, la mexicana, junto a la cual sobreviven bien que mal una serie de etnias, reconocidas oficialmente, y unas cuantas naciones adicionales, no reconocidas oficialmente como tales. ${ }^{9}$ Así, pues, México es de iure un Estado uninacional y pluriétnico, aunque de facto es pluriétnico y plurinacional. No

8 Este ejemplo basta, a mi modo de ver, para percatarnos de cuán inverosímil es la tesis de algunos negacionistas "moderados", quienes aseveran que el concepto de nación sólo tiene aplicación, en el mejor de los casos, a partir de la Revolución Francesa.

9 En su aportación a este volumen (pp. 149-153), Villoro da como ejemplo de nación dentro del Estado mexicano a los huicholes, a diferencia de, por ejemplo, los otomíes, que sólo constituirían una etnia. Supongo que, de acuerdo con los criterios que Villoro y yo compartimos, podrían detectarse otras naciones "indígenas" más en México. Pero como no soy experto en 
creo que significara una catástrofe cósmica el que ese de facto se convirtiera también en un de iure sin que cambiara gran cosa la Constitución del Estado en sí mismo (con lo cual, de paso se daría un buen ejemplo al resto de los Estados latinoamericanos, y no sólo a ellos). Pero claro que esto es una cuestión que han de decidir en definitiva los ciudadanos de los Estados Unidos Mexicanos... y no un filósofo de identidad nacional dudosa que se encuentra a diez mil kilómetros de distancia. Aquí concluyo, pues, mi Breve Historia General de México, que espero le guste a Velasco.

Una última puntualización a las observaciones críticas de Velasco. Él me atribuye "el principio político liberal 'a cada nación un Estado, y en cada Estado una sola nación' que ha justificado la consolidación de los Estados nacionales etnocráticos" (Velasco, op. cit., p. 145). Como creo que muestra mi breve análisis del caso mexicano, mi teoría no lleva consigo este principio "liberal". Al contrario: ya en $M N$ (p. 103) indico que la solución ideal a muchos conflictos actuales sería la aceptación de Estados multinacionales no hegemónicos (o no etnocráticos, en la terminología Stavenhagen-Velasco). Lo que advertía en mi ensayo, no obstante, es que, por razones históricas contingentes (básicamente: la testarudez, la arrogancia y el egoísmo de las naciones mayoritarias dentro de un Estado hegemónico), este ideal es muy difícil de alcanzar. Pero en mi artículo daba incluso algunos ejemplos donde el ideal "un Estado-varias naciones en pie de igualdad" se había logrado realizar bastante bien: Finlandia y Suiza en Europa; podríamos añadir Canadá en América, y quizás haya algún otro ejemplo por ahí que se me escapa. En todo caso, no hay que perder las esperanzas de multiplicar tales ejemplos, y nada en mi teoría implica que debamos perderlas, al contrario. El ser humano es malo, pero perfectible $-\mathrm{y}$ vale la pena intentarlo. Creo que en esto Velasco y yo coincidimos plenamente.

\section{AD VILLORO}

Mis respuestas a Villoro serán aún más escuetas porque hay acuerdo en (casi) toda la línea, aunque partimos de esquemas conceptuales algo distintos y usamos terminologías algo diferentes.

Creo que Villoro es un nacionalista igual que yo; no obstante, parece que prefiere que no le apliquen este calificativo. La razón de ello sería que el término se usa hoy en día de forma peyorativa (cfr. Villoro, op. cit., p. 151). Ahora bien, con perdón de Villoro, ésta no es una buena razón para un intelectual crítico. Si creemos que el uso peyorativo de un término es injusto con respecto a aquellos a quienes se les aplica, como intelectuales críticos

la materia, dejo a Villoro o a otros autores mejor informados que yo la tarea de completar la lista. 
estamos en la obligación de objetar a ese uso (aunque esté divulgado) y promover al menos un uso neutral. No hace muchos años todavía, el término "homosexual" se utilizaba muy peyorativamente. Desde entonces, las cosas han cambiado - gracias, entre otras cosas, a la encomiable labor crítica de muchos autores, fueran o no homosexuales-y hoy día nadie tiene por qué ruborizarse de que le apliquen el calificativo en cuestión. Quizás algún día los criptonacionalistas — que son la inmensa mayoría de los habitantes del planeta- culminen con éxito un proceso de outing y puedan declararse abiertamente nacionalistas sin tener por qué ruborizarse o atraer anatemas sobre sus cabezas.

Una divergencia terminológica más esencial, porque es en parte de origen conceptual, es la siguiente. El término "Estado" lo utilizamos Villoro y yo de la misma manera: como unidad jurídico-administrativa que en sí no tiene nada que ver con etnias ni naciones. El término "nación" lo empleamos de manera muy parecida, como unidad en lo esencial político-cultural. Las divergencias aparecen en el uso del término "etnia". Mientras que en MEN "etnia" aparece como el término primitivo supraordenado al término "nación" (o sea, formalmente: el conjunto de las naciones es un subconjunto propio del conjunto de las etnias -el lector alérgico a la teoría de conjuntos sabrá perdonar esta pedantería), en Villoro "etnia" y "nación" son términos mutuamente excluyentes (para el lógico pedante: el conjunto de las etnias $\mathrm{y}$ el de las naciones son disjuntos). A cambio, tanto el concepto de etnia como el de nación se subordinan al concepto más general de pueblo (que en Villoro, conceptualmente, tampoco tiene nada que ver con el concepto de Estado). Simplificando: las naciones son pueblos con autoconciencia política, las etnias son pueblos sin autoconciencia política. ${ }^{10}$

Villoro advierte que su terminología tiene la ventaja de concordar mejor con los usos del Derecho "Internacional" (es decir, Interestatal); como cuando se habla del derecho de autodeterminación de los pueblos. En esto tiene razón; y como soy hombre siempre dispuesto a compromisos, no tendría mayor inconveniente en aceptar la terminología villoriana. No obstante, antes de dar la batalla terminológica por definitivamente perdida, quisiera advertir del carácter descorazonadoramente polisémico del término "pueblo". Hay muchos usos de "pueblo" que tienen poco o nada que ver con aquello en lo que Villoro piensa; por ejemplo:

a) "pueblo" como aglomeración de viviendas;

10 Villoro admite que puede utilizarse a veces el término "etnia" como pueblo con un proyecto político compartido, pero que en tal caso equivale a "nación" (p. 151). Como este uso de "etnia" sería redundante, podemos olvidarnos de él. 
b) "pueblo" en la frase "pueblo soberano" —es decir, el conjunto de los ciudadanos de un Estado democrático, sea cual sea su etnia, nación o "pueblo" en el sentido villoriano;

c) "pueblo" como vasta clase social ("los de abajo"), por oposición a los aristócratas, o los ricos, o los mandamases en general, como en el eslogan: "el pueblo unido jamás será vencido".

En vistas de este inapetitoso conglomerado de usos de la palabra, preferí en $M N$ utilizar "etnia", un término menos cargado de connotaciones y que, hasta donde alcanzo a ver, los etnólogos modernos utilizan cada vez más como un término teórico amplio, que incluye mucho más que ciertas tribus "primitivas" perdidas en Nueva Guinea o Amazonia. Sea como fuere, repito que esta divergencia terminológica no debería ser un casus belli, y el lector que simpatice más con la propuesta villoriana, puede sustituir mi término "etnia" sistemáticamente por el de "pueblo". (Y lo que Villoro llama "etnias" sería lo que yo describo como "etnias que (aún o ya) no son naciones".)

En lo que creo que hay un error de fondo es en la primera observación crítica de Villoro, según la cual yo rechazo la propuesta que él hace de indicar factores observables objetivamente, como la lengua, las formas de vida, las instituciones culturales, etc., para identificar etnias y naciones. Esto es un flagrante malentendido. La teoría MEN afirma explícitamente que debemos hacer uso de esos fenómenos observables, pero sólo como síntomas, y no como condiciones de definición de etnias y naciones. Y ello precisamente porque los conceptos de etnia y nación son conceptos teóricos en el sentido de la clásica filosofía de la ciencia. Para ponerlo en términos un poco formales (perdón de nuevo al lector antiformalista), lo que la teoría MEN dice es que no podemos esperar una definición del tipo: "Para todo grupo humano $x, x$ es una nación si y sólo si: $A_{1}(x) \wedge \ldots \wedge A_{n}(x)$ ", donde $A_{1}, \ldots A_{n}$ son una serie de predicados observacionales (referidos a la lengua hablada, los ritos religiosos seguidos, los platillos cocinados, etc.) objetivamente detectables e instanciables en cada $x$. En este sentido, el concepto de nación es más plástico y rico que la mera conyunción (o disyunción) de $A_{1}, \ldots A_{n} \cdot{ }^{11}$ Pero claro que, aunque "nación" no se deje definir mediante $A_{1}, \ldots A_{n}$, necesitaremos la aplicación de al menos algunos de estos $A_{i}$ para averiguar (provisional e hipotéticamente) de qué nación se trata. (Esto, por cierto, es independiente de la cuestión acerca de la "objetividad" o "subjetividad" de los factores nacionales que parece preocuparle a Villoro.)

11 Éste fue el famoso "descubrimiento" de Carnap, Hempel \& Co. en los años 1940 y 1950 acerca de la semántica de los términos teóricos (tesis del surplus meaning de los términos teóricos respecto de los observacionales). 
Otro malentendido villoriano respecto a mi posición es su observación 6, según la cual yo estoy en contra de un Estado plural o multicultural por sí mismo. Como ya hemos visto que Velasco me atribuye una salvajada análoga, infiero que soy yo mismo el culpable del malentendido por no haber formulado mi posición en $M N$ con la suficiente claridad. Sólo puedo repetir la precisión ya hecha a Velasco y quizás remachar el clavo con la siguiente declaración enfática: el ideal supremo de un nacionalista internacionalista no puede ser otro que el de un solo Estado Mundial en el que las seiscientas y tantas naciones que actualmente componen la humanidad sean todas tratadas de igual a igual —en el que inuits, québecois, chicanos, huicholes, mayas, quechuas, guaraníes, mapuches, escoceses, irlandeses, bretones, corsos, vascos, catalanes, kosovares, chechenos, kurdos, palestinos, bereberes, saharauis, la mayoría de las naciones del África subsahariana, tamiles, sikhs, tibetanos, maoríes, etc., etc., etc. (ofrezco disculpas a las docenas de naciones sin Estado que la falta de espacio o de conocimientos me impiden mencionar aquí en vez de los "etc."), en el que todas esas naciones actualmente sin Estado propio se sientan igual de a gusto que las naciones que ahora disponen de un Estado propio. Ahora bien, estoy seguro de que tanto Villoro como Velasco admitirán que el camino que hay que recorrer para llegar hasta allí todavía es muy largo, si es que logramos recorrerlo algún día (el Estado Mundial que parece avecinarse, por el contrario, es de muy diversa índole...). Mientras no alcancemos esa meta, Estados de medianas proporciones realmente multinacionales y no hegemónicos pueden ser ciertamente la solución transitoria; pero cuando incluso este proyecto fracasa estrepitosamente, como por desgracia sigue ocurriendo todos los días, entonces no hay por qué rasgarse las vestiduras si algunas naciones se cansan de esperar y se esfuerzan por construir su propio Estado. En este contexto es sintomático que los voceros de las minorías nacionales de Europa Occidental suelan ser los más fervientes partidarios de una Unión Europea como verdadero Estado multinacional (y no como el club de Estados hegemónicos que es en la actualidad).

Por lo demás, la tesis de Villoro según la cual "Si queremos acabar con el nacionalismo hegemónico, tenemos que cercenar su raíz: el Estado-nación homogéneo" (p. 152) me parece injusta además de precipitada. Hay numerosos ejemplos de Estados nacionalmente homogéneos que viven pacíficamente sin molestar a nadie. Costa Rica, Holanda, Eslovenia o Japón tendrán problemas sociales y políticos de toda índole, y un pasado más o menos turbio según los casos, pero en definitiva han aprendido la lección y, en la actualidad, no se les puede culpar ni de que, en el interior de sus fronteras, una nación hegemónica discrimine a otras (son Estados que administran 
su propia y única nación según reglas democráticas), ni de que agredan a otras naciones al exterior de sus fronteras. ${ }^{12}$ La homogeneidad nacional de un Estado no es, pues, sinónimo de agresividad. Y si cualquier otra nación del mundo todo lo que quiere es que la dejen vivir en paz en su propio Estado, como Eslovenia con sus dos millones de pacíficos habitantes, está en su perfecto derecho al reclamar un Estado propio y defenderlo una vez constituido. Esta exigencia "desmesurada", en definitiva, no es sino lo que reza el principio de autodeterminación de los pueblos, fijado como objetivo de la Carta Fundacional de las Naciones Unidas, de 1945, en su artículo 1, § 2: "desarrollar entre las naciones relaciones amistosas fundadas en el respeto al principio de igualdad de derechos de los pueblos (o sea, naciones, en mi terminología) y de su derecho a disponer de sí mismos" (el subrayado es mío).

No hacen falta grandes dotes hermenéuticas para interpretar que este artículo, que Villoro sin duda se conoce al dedillo, establece la posibilidad de que si una nación (o "pueblo") quiere "disponer de sí misma", o sea, constituir un Estado propio, por las razones que sean, está en su perfecto derecho a ello, aunque al vecino no le caiga simpática la idea.

Este artículo lo han firmado hasta el presente 190 Estados. Casi ninguno lo ha tomado en serio. Y lo peor es que la mayoría de los intelectuales de Occidente, a pesar de su tan cacareada tradición crítica, tampoco lo toman en serio (cuando no lo atacan directamente). En definitiva, el propósito de mi "Manifiesto nacionalista" no fue otro que explicitar y fundamentar lo que oficialmente desde 1945 han firmado casi todos los Estados de la Tierra. Quizás algún día, ellos se decidan a implementar de facto lo que han aceptado de iure. Y mientras no lo hagan, seguirá corriendo mucha sangre, sudor y lágrimas.

12 Es cierto que Japón aprendió la lección más tarde que los otros tres ejemplos. Pero más vale tarde que nunca... lo cual no puede decirse de los Estados hegemónicos actuales. 